\title{
Plasma levels of ghrelin, des-acyl ghrelin and LEAP2 in children with obesity: correlation with age and insulin resistance
}

\section{Antonela S Fittipaldi ${ }^{1}$, Julieta Hernández ${ }^{2}$, Daniel Castrogiovanni', Daniela Lufrano', Pablo N De Francesco', Verónica Garrido ${ }^{2}$, Patrick Vitaux ${ }^{3}$, María Victoria Fasano ${ }^{4,5}$, Jean-Alain Fehrentz ${ }^{6}$, Adriana Fernández ${ }^{2}$, María F Andreoli, ${ }^{4,7, *}$ and Mario Perello ${ }^{1, *}$}

\begin{abstract}
'Laboratorio de Neurofisiología, Instituto Multidisciplinario de Biología Celular (IMBICE), Consejo Nacional de Investigaciones Científicas y Técnicas (CONICET), Universidad Nacional La Plata (UNLP) y Comisión de Investigaciones Científicas de la Provincia de Buenos Aires (CIC-PBA), La Plata, Buenos Aires, Argentina, ${ }^{2}$ Servicio de Nutrición del Hospital de Niños de La Plata, La Plata, Buenos Aires, Argentina, ${ }^{3}$ Bertin Technologies, Montigny Le Bretonneux, France, ${ }^{4}$ nstituto de Desarrollo e Investigaciones Pediátricas (IDIP), Hospital de Niños de La Plata - CIC-PBA, La Plata, Buenos Aires, Argentina, ${ }^{5}$ Departamento de Matemática, Facultad de Ciencias Exactas, UNLP, La Plata, Buenos Aires, Argentina, ${ }^{6}$ nstitut des Biomolécules Max Mousseron, UMR 5247 CNRS-Université Montpellier-ENSCM, Faculté de Pharmacie, Montpellier, France, and ${ }^{7}$ CONICET, La Plata, Buenos Aires, Argentina

*(M F Andreoli and M Perello contributed equally to this work)

Correspondence should be addressed to M F Andreoli or M Perello Email

mfandreoli@fbcb.unl.edu.ar or mperello@imbice.gov.ar
\end{abstract}

\begin{abstract}
Objective: The octanoylated peptide hormone ghrelin regulates appetite and glycaemic control. Des-acyl ghrelin abolishes some effects of ghrelin, but does not bind to ghrelin receptor. LEAP2 is a novel ligand for ghrelin receptor that blocks the effects of ghrelin. Some evidences show that plasma levels of these peptides are altered in adults with obesity, but their levels in childhood obesity remain poorly studied. Therefore, the objective of this study was to assess fasting plasma levels of ghrelin, des-acyl ghrelin and LEAP2 in children with normoweight, overweight/obesity and their association with different anthropometric and metabolic variables.

Design: A total of 42 females and 40 males, ages 3-12 years old were enrolled as a cross-sectional cohort.

Results: Plasma levels of des-acyl ghrelin and LEAP2 (but not ghrelin) were lower and ghrelin/des-acyl ghrelin ratio was higher in children with overweight/obesity. Des-acyl ghrelin negatively correlated with age, BMI z-score, insulin and HOMA index, and the correlations were stronger in children with overweight/obesity. LEAP2 levels negatively correlated with BMI z-score. No gender differences were found.

Conclusions: Our findings suggest that ghrelin tone is increased in childhood obesity, due to a decrease on plasma levels of des-acyl ghrelin and LEAP2, and that des-acyl ghrelin is associated to insulin resistance, particularly in children with overweight/obesity.
\end{abstract}

\section{Introduction}

Ghrelin is a gastrointestinal tract-derived hormone that acts via the growth hormone secretagogue receptor (GHSR) (1). Ghrelin is a 28-residue peptide that contains an n-octanoyl ester at its third serine residue, an unusual posttranslational modification catalyzed by the enzyme ghrelin O-acyltransferase (2). This lipid modification is essential for the bioactivity of ghrelin (1). Administration of ghrelin to healthy individuals increases hunger/food intake and promotes mechanisms that increase glycaemia (3). Administration of ghrelin decreases insulin secretion
(C) 2020 European Society of Endocrinology Printed in Great Britain
Published by Bioscientifica Ltd. 
(4) and increases plasma levels of growth hormone (GH), adrenocorticotropic hormone and cortisol (3). In plasma, ghrelin also exists as a des-octanoylated form, hereafter named des-acyl ghrelin (DAG). DAG is either secreted from ghrelin-producing cells of the gastrointestinal tract or results from ghrelin des-acylation in plasma (2). The role of DAG is uncertain since DAG does not bind to GHSR at physiological ranges, and no DAG receptor has been identified, yet. Strikingly, DAG modulates genes involved in glucose and lipid metabolism in mice lacking GHSR, suggesting a GHSR-independent action (5). In humans, plasma DAG levels are higher than ghrelin levels, and some studies show that DAG infusion improves glucose metabolism $(6,7)$ and that concomitant administration of DAG and ghrelin abolishes the hyperglycaemic effects of ghrelin (8). However, other studies could not confirm such observations (9). Recently, liver antimicrobial peptide 2 (LEAP2) has been identified as another ligand of GHSR (10). LEAP2 is a 40-residue peptide primarily secreted by the liver and jejunum (10). LEAP2 blocks ghrelin-induced activation of GHSR and also reduces GHSR constitutive activity $(11,12)$. In mice, LEAP2 blocks the stimulatory effects of ghrelin on food intake and GH secretion, and plasma LEAP2 levels display an inverse relationship to plasma ghrelin levels: LEAP2 levels decrease under fasting and increase to basal levels upon refeeding (10).

The accurate assessment of ghrelin in plasma has been proved to be challenging. Initial studies investigating plasma ghrelin levels in human samples reported ghrelin plus DAG levels (usually referred to as total ghrelin), as the early available commercial immunoassays did not discriminate the acylated and desacylated forms of the peptide $(13,14)$. Only the subsequent development of immunoassays to specifically assess ghrelin or DAG allowed the independent quantification of these two peptides in plasma. The assessment of ghrelin is also affected by the instability of the octanoyl modification since the ester bond is highly susceptible to be spontaneously hydrolysed at physiological $\mathrm{pH}$ and also a substrate of plasma esterases that rapidly des-acylate ghrelin (15). Only recently the methods of collection, handling and storage of plasma samples have been standardized for the correct assessment of ghrelin (14).

Different studies show an association between ghrelin and obesity. In adults, ghrelin levels decrease in patients with obesity and negatively correlate with BMI $(16,17)$. Ghrelin levels also decrease in children and adolescents with obesity (18) and negatively correlate with BMI (13, $19,20,21)$. Notably, only few studies have independently assessed ghrelin and DAG levels in children with obesity, and observations have been inconsistent $(13,19,22,23$, 24). Many studies found that ghrelin levels negatively correlate with circulating insulin and insulin resistance in adults and children $(13,24,25,26,27)$. In contrast, studies looking for associations between plasma ghrelin and circulating lipids have reported inconsistent results $(24,28,29,30,31)$. Thus, it seems evident that more clinical studies performing careful biochemical analyses in diverse human populations are still necessary for a better understanding of the implications of the ghrelin system in human beings. Regarding LEAP2, a recent study reports that LEAP2 levels are higher in patients with morbid obesity and positively correlate with BMI and plasma glucose (32). To our knowledge, plasma LEAP2 levels have not been investigated in children.

As a manoeuvre to assess the status of the ghrelin system, plasma levels of ghrelin and DAG have been combined to generate several indices. The sum of ghrelin plus DAG could be considered indicative of the total ghrelin production. Since DAG appears to be a functional inhibitor of ghrelin $(7,15)$, the ghrelin/DAG ratio has been used to estimate the effective ghrelin tone. Some studies show that the ghrelin/DAG ratio is a useful biomarker of excessive weight gain, even prior to the start of hyperphagia in subjects with Prader-Willi syndrome (13). Increased ghrelin/DAG ratio is also linked to obesity and diabetes $(13,19,33,34,35)$. Since LEAP2 blocks ghrelin actions, we hypothesized that the ghrelin/LEAP2 ratio could provide another estimation of the effective ghrelin tone. The aim of our study was to evaluate the plasma levels of ghrelin, DAG and LEAP2 in children with overweight or obesity and their association with different anthropometric and metabolic variables, investigating also a potential sexual dimorphism.

\section{Methods}

\section{Study design}

The study was approved by the Institutional Committee for the Revision of Research Protocols (CIRPI) of the Institute of Development and Paediatric Research (IDIP), La Plata Children's Hospital, and conducted according to the Declaration of Helsinki guidelines and Argentinian legal provisions governing clinical research on humans. Written informed consent and assent were obtained from all participants, as appropriate. Participants were recruited from the obesity program of the Nutrition Service at Sor María Ludovica Children's Hospital and from Elina 
de la Serna Children's Hospital (La Plata, Buenos Aires, Argentina), from April to December 2018.

\section{Study participants}

This cross-sectional cohort included 82 children, 3-12 years old, without chronic medical illness, a personal history of diabetes, history of medical condition, or medication related to obesity or diabetes risk status. Children were born with gestational age $>37$ weeks and birth weight $>2500 \mathrm{~g}$. Birth weight and gestational age were obtained from hospital records. All participants underwent a baseline evaluation, including a complete medical and family history and physical examination, including Tanner staging by a paediatrician. The study included only children at pre- or early-pubertal stages (Tanner stage I, II or III) and females who had not reached the menarche. Weight and height measurements were performed by nutrition staff. Weight was measured with the participants barefoot and wearing minimal clothing, on a mechanical scale (Co. AR. Me. Series E9637, Argentina) with a resolution of $10 \mathrm{~g}$ and expressed as Z-score and gender based on World Health Organisation (WHO) references according to the age (WAZ) (36). Height was measured with a Harpenden-type wall-mounted stadiometer (Holtain Ltd., United Kingdom) with a resolution of $1 \mathrm{~mm}$ and expressed as Z-score and gender based on WHO references according to the age (HAZ) (36). BMI was calculated by dividing weight by height squared $\left(\mathrm{kg} / \mathrm{m}^{2}\right)$ and expressed as Z-score and gender based on WHO references according to the age (BAZ) (36). As described by the WHO, children with a BAZ between -2 and +1 were considered normoweight (NW), above +1 BAZ were considered patients with overweight (OW), and above +2 BAZ were considered patients with obesity (OB) (36). Children with a BAZ lower than -2 were considered wasted and were not included in this study.

\section{Blood samples}

The participants were asked not to eat after 21:00 $\mathrm{h}$ the night before the session. Between 09:00 and 11:00 h, an overnight fasting blood sample was drawn from each child and collected on EDTA ( $1 \mathrm{mg} / \mathrm{mL}$ final) to measure plasma levels of glucose, insulin, total cholesterol (TC), high-density lipoprotein cholesterol (HDL-C), lowdensity lipoprotein cholesterol (LDL-C), very low density lipoprotein cholesterol (VLDL-C) and triacylglycerols (TG) levels. For ghrelin, DAG and LEAP2 determinations, blood samples were collected on EDTA ( $1 \mathrm{mg} / \mathrm{mL}$ final) and p-hydroxy-mercuribenzoic acid (0.4 mM final) and, then, plasmas were immediately acidified with $\mathrm{HCl}(0.1 \mathrm{~N}$ final) to preserve acylation (14). All samples were stored frozen at $-80^{\circ} \mathrm{C}$ until analysis.

\section{Laboratory analyses}

Glucose, TC, TG, LDL-C, VLDL-C and HDL-C levels were measured using standard enzymatic procedures in a TARGA BT3000 PLUS analyser (Biotecnica Instruments, Italy). Insulin levels were assessed by chemiluminescence (Access Beckman Coulter, Switzerland). Insulin resistance was estimated by the homeostasis model assessment for insulin resistance (HOMA index) (37). Ghrelin and DAG levels were assessed using specific enzyme immunoassays (A05306 and A05319, respectively, Bertin Bioreagent, Bertin Technologies, France). Assays were performed according to manufacturer's instructions. Briefly, $100 \mu \mathrm{L}$ of standards, quality controls and samples (diluted 1:2 or 1:5 in buffer for ghrelin or DAG determinations, respectively) were added to the plate as well as $100 \mu \mathrm{L}$ of the tracer antibody and incubated overnight at $4^{\circ} \mathrm{C}$. Following three washes, Ellman's reagent was added. After $60 \mathrm{~min}$, the absorbance was measured at $405 \mathrm{~nm}$ using a Packard SpectraCount BS10000 absorbance microplate reader (USA). LEAP2 levels were assessed using a specific enzyme immunoassay for human and mouse LEAP2 detection (EK-075-40, Phoenix Pharmaceutical, USA) according to manufacturer's instructions. This assay demonstrated linearity of dilution and parallelism and detected lower levels of LEAP2 in plasma samples from calorie-restricted mice (38). This LEAP2 ELISA assay kit has been recently validated in human samples (32). Briefly, $25 \mu \mathrm{L}$ of standards, quality controls and samples (diluted 1:25 in buffer) were incubated in the plate at room temperature with $50 \mu \mathrm{L}$ of antibody. After 2 h, $25 \mu \mathrm{L}$ of biotinylated LEAP2 were added and incubated overnight at $4^{\circ} \mathrm{C}$. Following several washes, horseradish peroxidase was added and incubated for $1 \mathrm{~h}$. Following three washes, 3,3',5,5'-tetramethylbenzidine was added and incubated for $1 \mathrm{~h}$. Finally, the reaction was stopped with $\mathrm{HCl}$ and absorbance was measured at $405 \mathrm{~nm}$ as described earlier. Ghrelin, DAG and LEAP2 levels were calculated from the corresponding calibration curves using logarithmic fitting in GraphPad Prism 5. Ghrelin+DAG levels were computed on a molar basis by adding ghrelin and DAG concentrations. Ghrelin/DAG ratio was computed on a molar basis as ghrelin concentration divided by DAG concentration. Ghrelin/LEAP2 ratio was computed on a molar basis as ghrelin concentration divided by LEAP2 concentration. 


\section{Statistics and data analyses}

Statistical analyses were performed using the R software, version 3.5.1. The Shapiro-Wilk test was applied to test whether variables showed a normal distribution. Variables normally distributed were summarized as mean \pm S.D., and nonparametric data were presented as median (interquartile range (IQR)). Since some variables were positively skewed, they were square root transformed (DAG, ghrelin and ghrelin+DAG) or log transformed (ghrelin/leap and ghrelin/DAG ratios, LEAP, insulin and HOMA index) for all subsequent analyses and expressed as mean $(95 \% \mathrm{CI})$ or geometric mean (95\% CI), respectively. Linear correlations between ghrelin levels and other variables were assessed using nonparametric (Spearman's) or parametric (Pearson's) correlations coefficients as appropriate. Comparisons between children with NW and children with OW/OB were conducted with $t$-test or Mann-Whitney for quantitative data and chi-square for categorical data. Differences between children with NW or OW/OB and gender were analysed with the use of two-way ANOVA using BAZ and gender as independent variables. The interaction term gender*BAZ was included in the ANOVA model and if it was considered not significant, the ANOVA was run again only with the main effects. Distribution of residuals was checked using the Shapiro-Wilk test and normal quantile plots. The statistical tests were two tailed, and the significance level was set at 5\%. In order to study interdependencies among ghrelin, DAG, LEAP2 and variables that showed significant correlation with any other variable (BAZ, insulin, TG, VLDL-C, LDL-C and HDL-C), a hierarchical clustering was performed. This data set was normalized with mean $=0$ and S.D. $=1$, and data from children with NW and children with $\mathrm{OW} / \mathrm{OB}$ were processed separately to construct their corresponding ordered heatmaps with dendrograms for participants and variables. The dendrograms were computed by agglomerative hierarchical clustering, using Euclidean distance metrics and group average as the similarity criterion. This analysis was performed using Orange software (39).

\section{Results}

\section{Characteristics of study subjects}

Among the 82 subjects, 36 (44\%) and 46 (66\%) children met BAZ criteria for NW or OW/OB, respectively. The OW/OB group included 18 children with $\mathrm{OW}$ and 28 children with $\mathrm{OB}$. Among children with $\mathrm{OB}, 21$ children had a BAZ between +2 and +4 , and 7 children had a BAZ higher than +4 . The study included $42(51 \%)$ females and $40(49 \%)$ males. Table 1 shows some characteristics of the participant children. The age and birth weight were similar between groups, while WAZ and BAZ were higher in children with $\mathrm{OW} / \mathrm{OB}$, as compared to children with $\mathrm{NW}$, as expected. Also, insulin levels and HOMA index were higher and HDL-C was lower in children with OW/ $\mathrm{OB}$, as compared to children with NW. The differences in HAZ between both groups, although statistically significant, are between the normal ranges. No changes were observed in other variables.

\section{Plasma levels of ghrelin, DAG and LEAP2}

Table 2 shows plasma levels of ghrelin, DAG and LEAP2 as well as indices based on these variables for children with $\mathrm{NW}$ or $\mathrm{OW} / \mathrm{OB}$, in all subjects and in male and female children separately. Ghrelin levels were similar between groups, while levels of DAG, ghrelin + DAG and LEAP2 were lower in children with $\mathrm{OW} / \mathrm{OB}$, as compared to children with NW, independently of the gender. Ghrelin/DAG ratio was higher in children with $\mathrm{OW} / \mathrm{OB}$, as compared to children with $\mathrm{NW}$, independently of the gender. Ghrelin/LEAP2 ratio did not differ between groups. As the interaction term gender*BAZ was not significant in any comparison, it was excluded from the ANOVA.

\section{Correlation analyses}

First, variables shown in Table 1 were subjected to correlation analyses with variables shown in Table 2 . Results of correlation analyses are shown in Table 3. When all subjects were analysed together, ghrelin levels did not correlate with any assessed variable. In contrast, DAG, LEAP2 and ghrelin + DAG levels as well as the ratio of ghrelin/DAG significantly correlated with different variables. In particular, DAG levels negatively correlated with age, BAZ, glycaemia $(r=-0.24, P=0.0307)$, insulin levels and HOMA index. Ghrelin+DAG levels positively correlated with age, BAZ, insulin levels and HOMA index, but did not correlate with glycaemia. LEAP2 levels negatively correlated with BAZ and birth weight $(r=-0.27$, $P=0.0147)$. Ghrelin/DAG ratio positively correlated with age, BAZ, insulin levels and HOMA index, while ghrelin/ LEAP2 ratio did not correlate with any assessed variable. For the lipid panel, no significant correlations were found with the exception of LEAP2 levels that negatively correlated only with LDL-C levels. No significant correlations were found between ghrelin, DAG, LEAP2 or their indices and HAZ in any case. 
Table 1 Baseline characteristics of patients.

\begin{tabular}{l}
\hline \\
\hline Age (years) \\
Birthweight (g) \\
WAZ \\
HAZ \\
BAZ \\
Insulin ( $\mu l \mathrm{l} / \mathrm{mL})$ \\
Glucose $(\mathrm{mmol} / \mathrm{L})$ \\
HOMA index \\
Total cholesterol (mg/dL) \\
HDL-C (mg/dL) \\
LDL-C (mg/dL) \\
VLDL-C (mg/dL) \\
TG (mg/dL)
\end{tabular}

\begin{tabular}{c}
$\mathbf{N} \mathbf{N}$ \\
\hline $7.56 \pm 2.41$ \\
$3491.4 \pm 352.1$ \\
$-\mathbf{0 . 4 2} \pm \mathbf{0 . 7 4}$ \\
$-\mathbf{0 . 6 0} \pm \mathbf{1 . 0 9}$ \\
$\mathbf{0 . 3 3}(-\mathbf{0 . 3 5} \mathbf{0 . 6 0 )}$ \\
$\mathbf{2 . 9 5}(\mathbf{2 . 3 8 ;} \mathbf{3 . 6 4 )}$ \\
$4.45 \pm 0.43$ \\
$\mathbf{0 . 5 8}(\mathbf{0 . 4 6 ; 0 . 7 2 )}$ \\
$1.57 \pm 0.22$ \\
$\mathbf{0 . 4 8} \pm \mathbf{0 . 0 9}$ \\
$0.91 \pm 0.24$ \\
$0.15(0.12 ; 0.19)$ \\
$0.74(0.58 ; 0.93)$
\end{tabular}

\begin{tabular}{c}
\hline \multicolumn{1}{c}{ OW/OB } \\
\hline $8.12 \pm 2.54$ \\
$3474.2 \pm 524.2$ \\
$\mathbf{2 . 6 1} \pm \mathbf{1 . 5 1}$ \\
$\mathbf{0 . 5 1} \pm \mathbf{1 . 1 0}$ \\
$\mathbf{2 . 8 5}(\mathbf{1 . 9 2 ; 3 . 5 1 )}$ \\
$\mathbf{7 . 6 0}(\mathbf{5 . 7 4 ;} \mathbf{1 0 . 0 7 )}$ \\
$4.52 \pm 0.49$ \\
$\mathbf{1 . 5 2}(\mathbf{1 . 1 4 ;} \mathbf{2 . 0 3 )}$ \\
$1.56 \pm 0.37$ \\
$\mathbf{0 . 4 4} \pm \mathbf{0 . 0 9}$ \\
$0.93 \pm 0.33$ \\
$0.16(0.12 ; 0.24)$ \\
$0.80(0.61 ; 1.17)$
\end{tabular}

\begin{tabular}{c}
\hline P value \\
\hline 0.269 \\
0.860 \\
$<\mathbf{0 . 0 0 0 1}$ \\
$<\mathbf{0 . 0 0 0 1}$ \\
$\mathbf{< 0 . 0 0 0 1}$ \\
$\mathbf{< 0 . 0 0 0 1}$ \\
0.508 \\
$<\mathbf{0 . 0 0 0 1}$ \\
0.898 \\
$\mathbf{0 . 0 3 7}$ \\
0.817 \\
0.121 \\
0.081
\end{tabular}

Data are presented as mean \pm s.D. for age, glucose, total cholesterol, HDL-C and LDL-C. Insulin and HOMA index are presented as geometric mean (95\% CI). BAZ, VLDL-C and TG are presented as median (IQR). Bold values are statistically significant $(P<0.05)$.

BAZ, BMI z-score; HAZ, height z-score; HDL-C, high-density lipoprotein cholesterol; HOMA, homeostatic model assessment; LDL-C, low-density lipoprotein cholesterol; TG, triglycerides; VLDL-C, very-low-density lipoprotein cholesterol; WAZ, weight z-score.

Next, the same correlation analyses described earlier were separately conducted in children with either NW or OW/OB (Table 3). Ghrelin levels did not correlate with any assessed variable in any of the groups. DAG levels negatively correlated with age, insulin levels and HOMA index in both groups of children, and the correlations were stronger in children with OW/OB vs NW. DAG levels negatively correlated with glycaemia only in children with $\mathrm{NW}$ $(r=-0.39, P=0.0199)$, while it negatively correlated with BAZ and positively correlated with HDL only in children with OW/OB. Ghrelin+DAG levels negatively correlated with age in both groups of children. Ghrelin+DAG levels negatively correlated with $\mathrm{BAZ}$, insulin levels and HOMA index and positively correlated with HDL levels only in children with OW/OB. LEAP2 levels negatively correlated with BAZ only in children with NW, while it negatively correlated with birth weight $(r=-0.37, P=0.0122)$ only in children with OW/OB. Ghrelin/DAG ratio positively correlated with age in both groups of children and with insulin levels and HOMA index only in children with OW/OB. The ghrelin/LEAP2 ratio did not correlate with any assessed variable in any group. For the lipid panel, no significant correlations were found with the exception of LEAP2 levels that negatively correlated with LDL-C levels only in children with OW/OB.

Finally, correlation analyses of the same variables described earlier were separately conducted in male and female children (Table 4). Ghrelin levels did not correlate with any assessed variable in male or female children. DAG and ghrelin+DAG levels negatively correlated

Table 2 Plasma levels of ghrelin, DAG and LEAP2 and their indices in all the subjects and in male and female children.

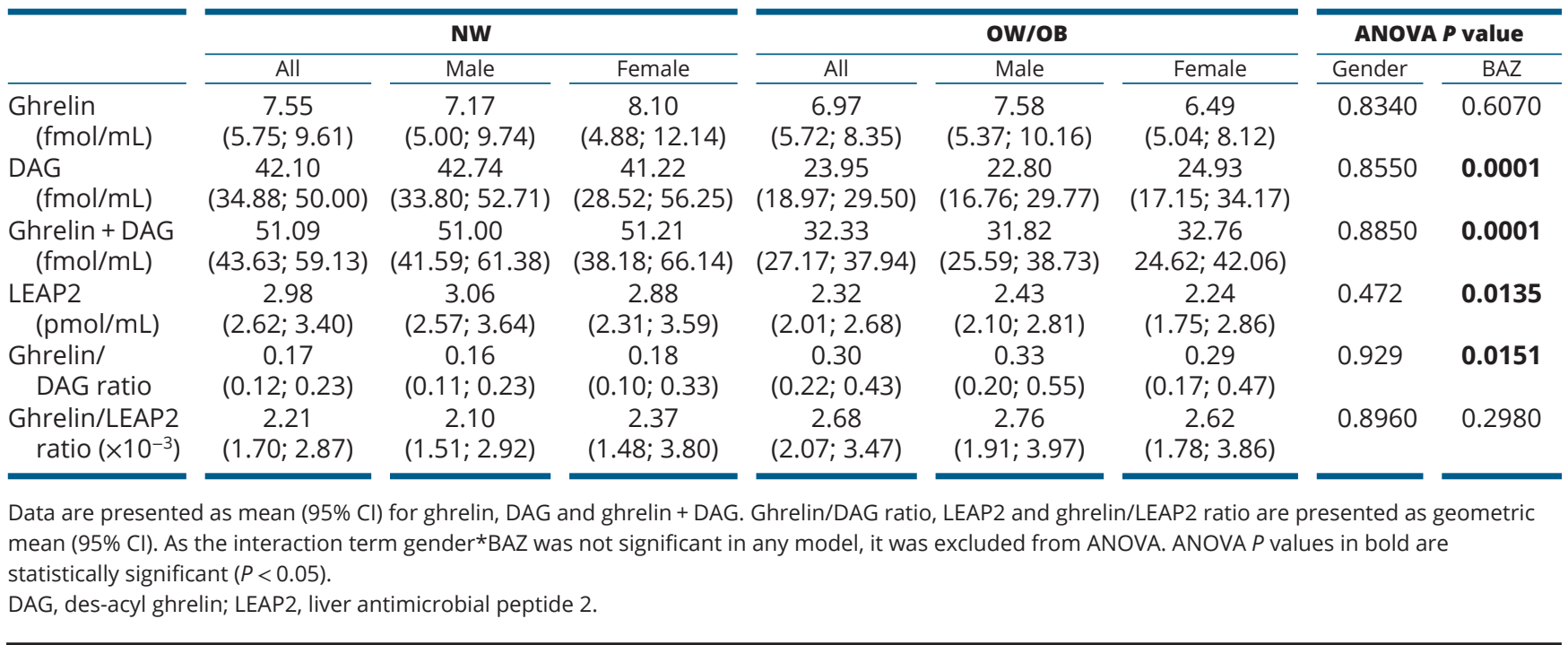


Table 3 Correlations between DAG and LEAP2 and calculated indices with age, BAZ, insulin, HOMA index and LDL-C in all the subjects and in children with NW or OW/OB.

\begin{tabular}{|c|c|c|c|c|}
\hline & Group & Ghrelin & DAG & Ghrelin + DAG \\
\hline \multirow[t]{3}{*}{ Age } & All & -0.01 & -0.58 & -0.58 \\
\hline & NW & 0.06 & -0.51 & -0.50 \\
\hline & OW/OB & -0.07 & -0.66 & -0.66 \\
\hline \multirow[t]{3}{*}{$\mathrm{BAZ}$} & All & -0.1 & -0.48 & -0.50 \\
\hline & NW & -0.29 & -0.14 & -0.26 \\
\hline & OW/OB & -0.14 & -0.32 & -0.33 \\
\hline \multirow[t]{3}{*}{ Insulin } & All & 0.08 & -0.59 & -0.52 \\
\hline & NW & 0.00 & -0.34 & -0.24 \\
\hline & OW/OB & 0.16 & -0.59 & -0.50 \\
\hline \multirow[t]{3}{*}{ HOMA index } & All & 0.1 & -0.59 & -0.51 \\
\hline & NW & 0.00 & -0.35 & -0.25 \\
\hline & OW/OB & 0.18 & -0.60 & -0.50 \\
\hline \multirow[t]{3}{*}{ LDL-C } & All & -0.04 & 0.01 & 0.00 \\
\hline & NW & -0.10 & 0.18 & 0.13 \\
\hline & OW/OB & 0.02 & -0.08 & -0.08 \\
\hline \multirow[t]{3}{*}{ HDL-C } & All & -0.02 & 0.15 & 0.13 \\
\hline & NW & -0.09 & -0.24 & -0.30 \\
\hline & OW/OB & -0.11 & 0.34 & 0.31 \\
\hline
\end{tabular}

$\begin{array}{r}\hline \text { LEAP2 } \\ \hline 0.04 \\ -0.11 \\ 0.14 \\ -\mathbf{0 . 3 5} \\ -\mathbf{0 . 4 0} \\ -0.07 \\ 0.03 \\ 0.10 \\ 0.25 \\ 0.04 \\ 0.08 \\ 0.27 \\ -\mathbf{0 . 2 6} \\ -0.20 \\ -\mathbf{0 . 3 1} \\ -0.11 \\ -0.10 \\ -0.21 \\ \hline\end{array}$

\begin{tabular}{c}
\hline Ghrelin/DAG \\
\hline $\mathbf{0 . 4 0}$ \\
$\mathbf{0 . 3 3}$ \\
$\mathbf{0 . 4 7}$ \\
$\mathbf{0 . 2 7}$ \\
-0.15 \\
0.19 \\
$\mathbf{0 . 4 8}$ \\
0.19 \\
$\mathbf{0 . 5 6}$ \\
$\mathbf{0 . 4 9}$ \\
0.20 \\
$\mathbf{0 . 5 7}$ \\
-0.02 \\
-0.20 \\
0.07 \\
0.16 \\
-0.11 \\
0.27
\end{tabular}

\begin{tabular}{r}
\hline Ghrelin/LEAP2 \\
\hline-0.04 \\
0.12 \\
-0.16 \\
0.05 \\
-0.10 \\
-0.13 \\
0.07 \\
-0.03 \\
0.01 \\
0.07 \\
-0.05 \\
0.01 \\
0.15 \\
0.16 \\
0.19 \\
0.06 \\
-0.02 \\
0.14
\end{tabular}

Bold values are statistically significant $(P<0.05)$.

BAZ, BMI Z-score; DAG, des-acyl ghrelin; HDL-C, high-density lipoprotein cholesterol; HOMA, homeostatic model assessment; LDL-C, low-density lipoprotein cholesterol; LEAP2, liver antimicrobial peptide 2; NW, normoweight; OW/OB, overweight/obese.

Table 4 Correlations between DAG and LEAP2 and calculated indices with age, BAZ, insulin, HOMA index, VLDL-C, LDL-C and TG in all the subjects and in male and female children.

\begin{tabular}{|c|c|c|c|c|}
\hline & Group & Ghrelin & DAG & Ghrelin + DAG \\
\hline \multirow[t]{3}{*}{ Age } & All & -0.01 & -0.58 & -0.58 \\
\hline & Male & 0.00 & -0.56 & -0.61 \\
\hline & Female & -0.05 & -0.60 & -0.57 \\
\hline \multirow[t]{3}{*}{ BAZ } & All & -0.10 & -0.48 & -0.50 \\
\hline & Male & -0.04 & -0.56 & -0.59 \\
\hline & Female & -0.20 & -0.38 & -0.43 \\
\hline \multirow[t]{3}{*}{ Insulin } & All & 0.08 & -0.59 & -0.52 \\
\hline & Male & 0.06 & -0.57 & -0.55 \\
\hline & Female & 0.03 & -0.60 & -0.55 \\
\hline \multirow[t]{3}{*}{ HOMA index } & All & 0.10 & -0.59 & -0.51 \\
\hline & Male & 0.08 & -0.59 & -0.55 \\
\hline & Female & 0.07 & -0.58 & -0.51 \\
\hline \multirow{3}{*}{ VLDL-C } & All & -0.09 & -0.21 & -0.19 \\
\hline & Male & -0.20 & 0.03 & 0.01 \\
\hline & Female & -0.03 & -0.44 & -0.41 \\
\hline \multirow[t]{3}{*}{ LDL-C } & All & -0.04 & 0.01 & 0.00 \\
\hline & Male & -0.23 & 0.34 & 0.23 \\
\hline & Female & 0.17 & -0.32 & -0.26 \\
\hline \multirow[t]{3}{*}{ HDL-C } & All & -0.02 & 0.15 & 0.13 \\
\hline & Male & 0.03 & 0.12 & 0.11 \\
\hline & Female & -0.05 & 0.15 & 0.15 \\
\hline \multirow[t]{3}{*}{ TG } & All & -0.09 & -0.17 & -0.15 \\
\hline & Male & -0.21 & 0.02 & 0.00 \\
\hline & Female & 0.03 & -0.34 & -0.33 \\
\hline
\end{tabular}

$\begin{array}{r}\hline \text { LEAP2 } \\ \hline 0.04 \\ 0.01 \\ 0.07 \\ -0.35 \\ -0.45 \\ -0.25 \\ 0.03 \\ 0.02 \\ 0.09 \\ 0.04 \\ -0.02 \\ 0.09 \\ 0.02 \\ 0.18 \\ -0.03 \\ -0.26 \\ -0.22 \\ -0.28 \\ -0.11 \\ -0.13 \\ -0.10 \\ -0.05 \\ 0.12 \\ 0.13 \\ \hline\end{array}$

\begin{tabular}{c}
\hline Ghrelin/DAG \\
\hline $\mathbf{0 . 4 0}$ \\
$\mathbf{0 . 3 1}$ \\
$\mathbf{0 . 4 6}$ \\
$\mathbf{0 . 2 7}$ \\
$\mathbf{0 . 3 1}$ \\
0.23 \\
$\mathbf{0 . 4 8}$ \\
$\mathbf{0 . 3 8}$ \\
$\mathbf{0 . 5 5}$ \\
$\mathbf{0 . 4 9}$ \\
$\mathbf{0 . 4 0}$ \\
$\mathbf{0 . 5 6}$ \\
0.12 \\
-0.18 \\
$\mathbf{0 . 4 2}$ \\
-0.02 \\
$-\mathbf{0 . 4 1}$ \\
$\mathbf{0 . 3 9}$ \\
0.16 \\
0.07 \\
0.22 \\
0.08 \\
0.19 \\
$\mathbf{0 . 3 3}$
\end{tabular}

\begin{tabular}{c}
\hline Ghrelin/LEAP2 \\
\hline-0.04 \\
-0.03 \\
-0.07 \\
0.05 \\
0.15 \\
-0.08
\end{tabular}

Bold values are statistically significant $(P<0.05)$

BAZ, BMI Z-score; DAG, des-acyl ghrelin; HDL-C, high-density lipoprotein cholesterol; HOMA, homeostatic model assessment; LDL-C, low-density lipoprotein cholesterol; LEAP2, liver antimicrobial peptide 2; TG, triglycerides; VLDL-C, very low-density lipoprotein cholesterol. 
with age, BAZ, insulin levels and HOMA index in male and female children. Strikingly, DAG levels positively correlated with LDL levels only in male children and negatively correlated with TG, LDL-C and VLDL-C levels only in female children. Ghrelin +DAG levels negatively correlated with TG and VLDL-C levels only in female children. LEAP2 levels negatively correlated with BAZ only in male children, while it negatively correlated with birth weight $(r=-0.38, P=0.0162)$ only in female children. Ghrelin/DAG ratio positively correlated with age, insulin levels and HOMA index in both male and female children. In male children, ghrelin/DAG ratio negatively correlated with LDL-C levels and positively correlated with BAZ, while in female children, it negatively correlated with TG, LDL-C and VLDL-C levels. The ghrelin/LEAP2 ratio did not correlate with any assessed variable in any group.

\section{Study of interdependencies by agglomerative hierarchical clustering}

Hierarchical clustering showed that metabolic and anthropometric variables cluster differently in children with NW or with OW/OB (Fig. 1). In NW, ghrelin and LEAP2 clustered together as well as LDL and DAG. In children with OW/OB, ghrelin and LEAP2 are no longer clustered together, while DAG clusters with HDL.

\section{Discussion}

Here, we assessed the plasma levels of ghrelin, DAG and LEAP2 in children with NW or with OW/OB and investigated their association with anthropometric and metabolic variables. To our knowledge, this is the first clinical study that reports circulating levels of LEAP2, a recently discovered GHSR ligand, in a paediatric population. In addition, we explored the association of ghrelin/DAG and ghrelin/LEAP2 ratios with different anthropometric and metabolic variables.

The paediatric population under study included 46 children that met BAZ criteria for OW/OB. We found high plasma insulin levels and HOMA index in children with $\mathrm{OW} / \mathrm{OB}$, indicating insulin resistance. Also, we found that HDL-C was $8 \%$ lower, while total cholesterol, LDL-C and VLDL-C remained unchanged, showing that alterations in glucose homeostasis appear early in children with $\mathrm{OW} / \mathrm{OB}$, and they are more evident than changes in the lipid profile. These outcomes agree with the notion that decreased insulin sensitivity and dyslipidaemia can occur in children and adolescents as a result of obesity (40).
Also, we found lower DAG levels, a slight (8\%) but not significant reduction of ghrelin levels, and a consequent reduction of the ghrelin/DAG ratio and the ghrelin +DAG levels in children with OW/OB. To the best of our knowledge, ghrelin and/or DAG levels in children were independently assessed only in six studies $(13,19,22,23,24,35)$. A reduction of DAG levels has been consistently reported in adults $(33,41)$, adolescents $(22,23)$ and pre-pubertal children $(19,23)$ with obesity. In contrast, studies assessing ghrelin levels in individuals with obesity reported inconsistent results. Some studies found a significant decrease (33-45\%) of ghrelin levels in adults $(32,41,42)$ and pre-pubertal $(13,19,24)$ and pubertal children (19) with obesity. In contrast, and in agreement with our results, other studies reported a slight $(16 \%)$ or no reduction of ghrelin levels in adults (31, $33)$, children and adolescents $(22,23,35)$ with obesity. The reasons for the divergent findings are unknown, but may be related to methodological differences in plasma sampling and storage, which are critical for a hormone inherently unstable such as ghrelin. Importantly, we confirmed that ghrelin + DAG levels are decreased in individuals with OW/OB, as reported in most studies (16, $17,19,29)$. Since ghrelin is converted to DAG in plasma, the simultaneous assessment of ghrelin and DAG appears as a better estimation of the status of the ghrelin system. Interestingly, we found that plasma levels of ghrelin and DAG showed no gender differences in any condition, in line with previous studies in children $(19,24)$ and adults $(16,17)$. To our knowledge, plasma ghrelin +DAG levels show sexual dimorphism only in adolescents, when levels are higher in females than in males (27).

We show here, for the first time that lower LEAP2 levels are detected in children with OW/OB. No gender differences were found in plasma LEAP2 levels. Such observation suggests that obesity affects not only the predominance of ghrelin forms but also other GHSR ligands. LEAP2 blocks ghrelin effects $(11,12)$; thus, a reduction of LEAP2 levels in children with obesity would facilitate the orexigenic and diabetogenic effects of ghrelin. Interestingly, the levels of LEAP2 we detected in children with NW are similar to the levels recently reported in adults with NW (32). In contrast, this study found that plasma LEAP2 levels were similar between subjects with NW and subjects with obesity that had a BMI lower than $40 \mathrm{~kg} / \mathrm{m}^{2}$ (32). A significant elevation of plasma LEAP2 levels was only detected in patients with BMI higher than $40 \mathrm{~kg} / \mathrm{m}^{2}$ (32). Thus, plasma LEAP2 levels seem to be affected only under severe obesity conditions 
A

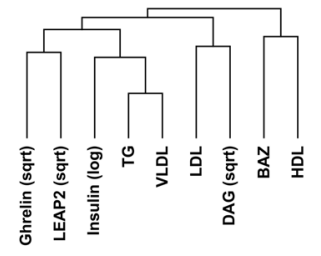

NW

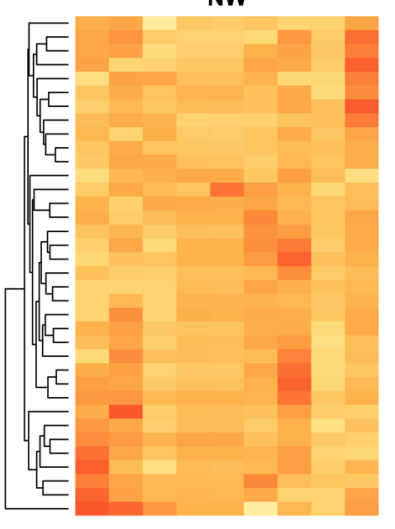

$-3.89$ 6.68
B
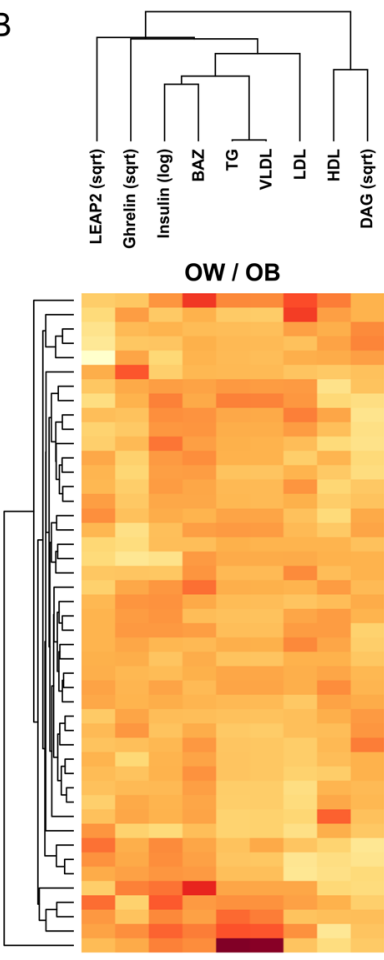

\section{Figure 1}

Agglomerative hierarchical clustering and heatmap diagram of ghrelin, DAG, LEAP2, BAZ, insulin, TG, VLDL, LDL and HDL in NW children (panel A) and in children with OW/OB (panel B). The metabolic and anthropometric variables (top row) and participants (left) are clustered hierarchically. Each column represents a variable and each row represents a participant in the study. Intensity of yellow or red colour represents low or high values, respectively, of the normalized data. A full colour version of this figure is available at https://doi.org/10.1530/ EJE-19-0684.

in adults. The reasons for the divergent results between adults and children are uncertain.

DAG and ghrelin+DAG negatively correlated with BAZ only in children with $\mathrm{OW} / \mathrm{OB}$, in a genderindependent manner. LEAP2 levels also correlated with $\mathrm{BAZ}$, and such correlation was significant only in male children and in children with NW. These observations suggest that the mechanisms that link the levels of DAG and LEAP2 to body weight are altered in children with OW/OB. Hierarchical clustering analysis also indicated that the interdependence of DAG and LEAP2 with other variables, including $\mathrm{BAZ}$, was different in children with OW/OB. Notably, DAG levels and levels of ghrelin +DAG negatively correlated with age, in a gender- and BAZindependent manner. Similar results were previously reported by other studies in diverse populations, many of which include adolescents $(13,19,21,43,44)$. Indeed, levels of ghrelin+DAG negatively correlated with the pubertal stage $(19,21)$. Overall, clinical data indicate that the ghrelin system plays a more relevant role at younger ages, when its regulatory effects on GH secretion could be more important. In line with this notion, studies in mice show that endogenous ghrelin modulates GH secretory episodes primarily during the rapid phase of growth (45). Still, it is worth mentioning that we found that levels of ghrelin, DAG or LEAP2 did not correlate with height (expressed as HAZ) in children, in agreement with other authors (21), suggesting that the plasma levels of these peptides are not directly linked to growth. The extent to which alterations of the ghrelin system affect the growth of children with OW/OB remains uncertain.

DAG levels negatively correlated with insulin and HOMA index, in a BAZ- and gender-independent manner. Levels of ghrelin + DAG also negatively correlated with insulin and HOMA index, but these correlations were significant only in children with $\mathrm{OW} / \mathrm{OB}$, in a genderindependent manner. Levels of ghrelin did not correlate with insulin and HOMA index, similarly as previously reported (33). Current observations are in line with the idea of a crosstalk between DAG and glycaemic control, which appears to be independent of obesity, and also highlight the beneficial role of DAG in glycaemic control that, in turn, may be dependent or independent of the inhibitory role of DAG on ghrelin effects $(6,7,8)$. Regarding the lipid profile, we mainly found weak associations. LEAP2 levels negatively correlated with LDL-C, and such correlation only showed statistical significance in children with $\mathrm{OW} /$ $\mathrm{OB}$ in a gender-independent manner. Thus, a potential role of LEAP2 in obesity-related dyslipidaemia should be further studied. DAG levels as well as ghrelin+DAG negatively correlated with TG, VLDL-C and LDL-C exclusively in females. DAG levels negatively correlated with LDL-C in females and positively correlated with LDL-C in males. Previous studies also reported similar weak correlations between circulating lipids and ghrelin, although no gender differences were reported $(24,28,29$, $30,31)$. The weakness of the detected associations limits the ability to provide any certain conclusion in this regard.

Here, we compared ghrelin/LEAP2 and ghrelin/ DAG ratios to determine their degree of association with different variables. The ghrelin/DAG ratio has been widely linked to obesity and insulin resistance $(13,19,33,34,35)$. In agreement with our results, several authors reported that this ratio is increased in patients with obesity, either adults (33), children or adolescents $(13,35)$. The increase of the ghrelin/DAG ratio occurs as a consequence of the 
reduction of DAG levels, an unbalance that would facilitate the orexigenic and diabetogenic effects of ghrelin in children with $\mathrm{OW} / \mathrm{OB}$, as previously discussed for LEAP2. As expected, the ghrelin/DAG ratio positively correlated with variables that negatively correlate with DAG. In particular, ghrelin/DAG ratio positively correlated with age (in a gender- and BAZ-independent manner), with BAZ (exclusively in male children, in a BAZ-independent manner) and with insulin levels and HOMA index (in the whole population, and in children with $\mathrm{OW} / \mathrm{OB}$, in a gender-independent manner). In adults, the observation that ghrelin/DAG ratio correlates with insulin and HOMA index only in patients with OW/OB has been proposed as an indication that the ghrelin/DAG ratio contributes to modulate insulin action in obese conditions (33). Since LEAP2 blocks constitutive and ghrelin-evoked GHSR signalling (11), we hypothesized that the ghrelin/LEAP2 ratio could be useful to estimate ghrelin tone in children with obesity. Notably, the above referred study assessing LEAP2 in adults found lower plasma ghrelin and higher plasma LEAP2 levels in patients with severe obesity and, as a consequence, the ghrelin/LEAP2 ratio was decreased in these patients (32). In contrast, we found that the ghrelin/ LEAP2 ratio remained unaffected in children with OW/ $\mathrm{OB}$, in a gender-independent manner, and it showed no correlation with any of the metabolic or anthropometric variables studied. Thus, the ghrelin/LEAP2 ratio did not provide any additional information in children.

In summary, we used specific commercial enzyme immunoassays to assess ghrelin, DAG and LEAP2 in plasma samples, which were carefully collected and stored, from fasted children with NW or OW/OB. We found that ghrelin levels did not differ between both groups, while DAG and LEAP2 decreased in children with OW/OB. Thus, we conclude that ghrelin tone is increased in childhood obesity, due to a decrease of plasma levels of DAG and LEAP2. Also, we found that DAG is associated to insulin resistance, particularly in children with OW/OB. Notably, no highly relevant gender differences were found.

\section{Declaration of interest}

The authors declare that there is no conflict of interest that could be perceived as prejudicing the impartiality of this study.

\section{Funding}

This work was supported by grants from the Fondo para la Investigación Científica y Tecnológica (FONCyT, PICT2016-1084, PICTO2017-0086 and PICT2017-3196), from CONICET (PUE-2017), from Fundación Alberto Roemmers and from the Commission for Scientific Research of the Province of Buenos Aires (FCCIC16) to M P. A S F was supported by CONICET.

\section{Author contribution statement}

$M F$ Andreoli and $M$ Perello contributed equally to this work. $P \vee, J A F, A F$, M F A, M P designed the study. A S F, J H, D C, D L, P N D F, V G, P V, M V F, J A F, A F, M F A, M P collected, analysed and/or interpreted the data. M F $A$ and $M P$ wrote the manuscript. All authors approved the submitted and published versions.

\section{References}

1 Kojima M, Hosoda H, Date Y, Nakazato M, Matsuo H \& Kangawa K. Ghrelin is a growth-hormone-releasing acylated peptide from stomach. Nature $1999 \mathbf{4 0 2}$ 656-660. (https://doi.org/10.1038/ 45230)

2 Yang J, Brown MS, Liang G, Grishin NV \& Goldstein JL. Identification of the acyltransferase that octanoylates ghrelin, an appetite-stimulating peptide hormone. Cell 2008132 387-396. (https://doi.org/10.1016/j.cell.2008.01.017)

3 Akamizu T, Takaya K, Irako T, Hosoda H, Teramukai S, Matsuyama A, Tada H, Miura K, Shimizu A, Fukushima M et al. Pharmacokinetics, safety, and endocrine and appetite effects of ghrelin administration in young healthy subjects. European Journal of Endocrinology 2004150 447-455. (https://doi.org/10.1530/eje.0.1500447)

4 Tong J, Prigeon RL, Davis HW, Bidlingmaier M, Kahn SE, Cummings DE, Tschop MH \& D'Alessio D. Ghrelin suppresses glucose-stimulated insulin secretion and deteriorates glucose tolerance in healthy humans. Diabetes 201059 2145-2151. (https:// doi.org/10.2337/db10-0504)

5 Delhanty PJ, Sun Y, Visser JA, van Kerkwijk A, Huisman M, van Ijcken WF, Swagemakers S, Smith RG, Themmen AP \& van der Lely AJ. Unacylated ghrelin rapidly modulates lipogenic and insulin signaling pathway gene expression in metabolically active tissues of GHSR deleted mice. PLOS ONE 20105 e11749. (https://doi. org/10.1371/journal.pone.0011749)

6 Benso A, St-Pierre DH, Prodam F, Gramaglia E, Granata R, van der Lely AJ, Ghigo E \& Broglio F. Metabolic effects of overnight continuous infusion of unacylated ghrelin in humans. European Journal of Endocrinology 2012166 911-916. (https://doi.org/10.1530/ EJE-11-0982)

7 Ozcan B, Neggers SJ, Miller AR, Yang HC, Lucaites V, Abribat T, Allas S, Huisman M, Visser JA, Themmen AP et al. Does des-acyl ghrelin improve glycemic control in obese diabetic subjects by decreasing acylated ghrelin levels? European Journal of Endocrinology 2014170 799-807. (https://doi.org/10.1530/EJE-13-0347)

8 Broglio F, Gottero C, Prodam F, Gauna C, Muccioli G, Papotti M, Abribat T, Van Der Lely AJ \& Ghigo E. Non-acylated ghrelin counteracts the metabolic but not the neuroendocrine response to acylated ghrelin in humans. Journal of Clinical Endocrinology and Metabolism 200489 3062-3065. (https://doi.org/10.1210/jc.2003031964)

9 Tong J, Davis HW, Summer S, Benoit SC, Haque A, Bidlingmaier M, Tschop MH \& D'Alessio D. Acute administration of unacylated ghrelin has no effect on Basal or stimulated insulin secretion in healthy humans. Diabetes 201463 2309-2319. (https://doi. org/10.2337/db13-1598)

10 Ge X, Yang H, Bednarek MA, Galon-Tilleman H, Chen P, Chen M, Lichtman JS, Wang Y, Dalmas O, Yin Y et al. LEAP2 is an endogenous antagonist of the ghrelin receptor. Cell Metabolism 2018;27 469461. e6-469.e6. (https://doi.org/10.1016/j.cmet.2017.10.016)

11 M'Kadmi C, Cabral A, Barrile F, Giribaldi J, Cantel S, Damian M, Mary S, Denoyelle S, Dutertre S, Peraldi-Roux S et al. N-terminal liver-expressed antimicrobial Peptide 2 (LEAP2) region exhibits inverse agonist activity toward the ghrelin receptor. Journal of Medicinal Chemistry 201962 965-973. (https://doi.org/10.1021/acs. jmedchem.8b01644) 
12 Wang JH, Li HZ, Shao XX, Nie WH, Liu YL, Xu ZG \& Guo ZY. Identifying the binding mechanism of LEAP2 to receptor GHSR1a. FEBS Journal 2019286 1332-1345. (https://doi.org/10.1111/ febs.14763)

13 Kuppens RJ, Diene G, Bakker NE, Molinas C, Faye S, Nicolino M, Bernoux D, Delhanty PJ, van der Lely AJ, Allas S et al. Elevated ratio of acylated to unacylated ghrelin in children and young adults with Prader-Willi syndrome. Endocrine 201550 633-642. (https://doi. org/10.1007/s12020-015-0614-x)

14 Hosoda H \& Kangawa K. Standard sample collections for blood ghrelin measurements. Methods in Enzymology 2012514 113-126. (https://doi.org/10.1016/B978-0-12-381272-8.00008-8)

15 Delhanty PJ, Huisman M, Julien M, Mouchain K, Brune P, Themmen AP, Abribat T \& van der Lely AJ. The acylated (AG) to unacylated (UAG) ghrelin ratio in esterase inhibitor-treated blood is higher than previously described. Clinical Endocrinology 201582 142-146. (https://doi.org/10.1111/cen.12489)

16 Shiiya T, Nakazato M, Mizuta M, Date Y, Mondal MS, Tanaka M, Nozoe S, Hosoda H, Kangawa K \& Matsukura S. Plasma ghrelin levels in lean and obese humans and the effect of glucose on ghrelin secretion. Journal of Clinical Endocrinology and Metabolism 200287 240-244. (https://doi.org/10.1210/jcem.87.1.8129)

17 Tschop M, Weyer C, Tataranni PA, Devanarayan V, Ravussin E \& Heiman ML. Circulating ghrelin levels are decreased in human obesity. Diabetes 200150 707-709. (https://doi.org/10.2337/ diabetes.50.4.707)

18 Reinehr T, de Sousa G \& Roth CL. Obestatin and ghrelin levels in obese children and adolescents before and after reduction of overweight. Clinical Endocrinology 200868 304-310. (https://doi. org/10.1111/j.1365-2265.2007.03042.x)

19 Bellone S, Prodam F, Savastio S, De Rienzo F, Demarchi I, Trovato L, Petri A, Rapa A, Aimaretti G \& Bona G. Acylated and unacylated ghrelin levels in normal weight and obese children: influence of puberty and relationship with insulin, leptin and adiponectin levels. Journal of Endocrinological Investigation 201235 191-197. (https://doi. org $/ 10.3275 / 7761)$

20 Soriano-Guillen L, Barrios V, Martos G, Chowen JA, Campos-Barros A $\&$ Argente J. Effect of oral glucose administration on ghrelin levels in obese children. European Journal of Endocrinology 2004151 119-121. (https://doi.org/10.1530/eje.0.1510119)

21 Whatmore AJ, Hall CM, Jones J, Westwood M \& Clayton PE. Ghrelin concentrations in healthy children and adolescents. Clinical Endocrinology 200359 649-654. (https://doi.org/10.1046/j.13652265.2003.01903.x)

22 Mackelvie KJ, Meneilly GS, Elahi D, Wong AC, Barr SI \& Chanoine JP. Regulation of appetite in lean and obese adolescents after exercise: role of acylated and desacyl ghrelin. Journal of Clinical Endocrinology and Metabolism 200792 648-654. (https://doi.org/10.1210/jc.20061028)

23 Pacifico L, Anania C, Poggiogalle E, Osborn JF, Prossomariti G, Martino F \& Chiesa C. Relationships of acylated and des-acyl ghrelin levels to bone mineralization in obese children and adolescents. Bone 200945 274-279. (https://doi.org/10.1016/j.bone.2009.04.204)

24 Razzaghy-Azar M, Nourbakhsh M, Pourmoteabed A, Nourbakhsh M, Ilbeigi D \& Khosravi M. An evaluation of acylated ghrelin and obestatin levels in childhood obesity and their association with insulin resistance, metabolic syndrome, and oxidative stress. Journal of Clinical Medicine 20165 E61. (https://doi.org/10.3390/ jcm5070061)

25 Cheng HL, Sainsbury A, Garden F, Sritharan M, Paxton K, Luscombe G, Hawke C \& Steinbeck K. Ghrelin and peptide YY change during puberty: relationships with adolescent growth, development, and obesity. Journal of Clinical Endocrinology and Metabolism 2018103 2851-2860. (https://doi.org/10.1210/ jc.2017-01825)
26 Ikezaki A, Hosoda H, Ito K, Iwama S, Miura N, Matsuoka H, Kondo C, Kojima M, Kangawa K \& Sugihara S. Fasting plasma ghrelin levels are negatively correlated with insulin resistance and PAI-1, but not with leptin, in obese children and adolescents. Diabetes 200251 3408-3411. (https://doi.org/10.2337/diabetes.51.12.3408)

27 Soriano-Guillen L, Ortega L, Navarro P, Riestra P, Gavela-Perez T $\&$ Garces C. Sex-related differences in the association of ghrelin levels with obesity in adolescents. Clinical Chemistry and Laboratory Medicine 201654 1371-1376. (https://doi.org/10.1515/cclm-20150555)

28 Park HS, Lee KU, Kim YS \& Park CY. Relationships between fasting plasma ghrelin levels and metabolic parameters in children and adolescents. Metabolism: Clinical and Experimental 200554 925-929. (https://doi.org/10.1016/j.metabol.2005.02.007)

29 Purnell JQ, Weigle DS, Breen P \& Cummings DE. Ghrelin levels correlate with insulin levels, insulin resistance, and high-density lipoprotein cholesterol, but not with gender, menopausal status, or cortisol levels in humans. Journal of Clinical Endocrinology and Metabolism 200388 5747-5752. (https://doi.org/10.1210/jc.2003030513)

30 Zou CC, Liang L \& Zhao ZY. Factors associated with fasting plasma ghrelin levels in children and adolescents. World Journal of Gastroenterology 200814 790-794. (https://doi.org/10.3748/ wjg.14.790)

31 Wadden D, Cahill F, Amini P, Randell E, Vasdev S, Yi Y, Zhang W $\&$ Sun G. Serum acylated ghrelin concentrations in response to short-term overfeeding in normal weight, overweight, and obese men. PLOS ONE 20127 e45748. (https://doi.org/10.1371/journal. pone.0045748)

32 Mani BK, Puzziferri N, He Z, Rodriguez JA, Osborne-Lawrence S, Metzger NP, Chhina N, Gaylinn B, Thorner MO, Thomas EL et al. LEAP2 changes with body mass and food intake in humans and mice. Journal of Clinical Investigation 2019129 3909-3923. (https:// doi.org/10.1172/JCI125332)

33 Barazzoni R, Zanetti M, Ferreira C, Vinci P, Pirulli A, Mucci M, Dore F, Fonda M, Ciocchi B, Cattin L et al. Relationships between desacylated and acylated ghrelin and insulin sensitivity in the metabolic syndrome. Journal of Clinical Endocrinology and Metabolism 200792 3935-3940. (https://doi.org/10.1210/jc.2006-2527)

34 Inhoff T, Monnikes H, Noetzel S, Stengel A, Goebel M, Dinh QT, Riedl A, Bannert N, Wisser AS, Wiedenmann B et al. Desacyl ghrelin inhibits the orexigenic effect of peripherally injected ghrelin in rats. Peptides 200829 2159-2168. (https://doi.org/10.1016/j. peptides.2008.09.014)

35 Vivenza D, Rapa A, Castellino N, Bellone S, Petri A, Vacca G, Aimaretti G, Broglio F \& Bona G. Ghrelin gene polymorphisms and ghrelin, insulin, IGF-I, leptin and anthropometric data in children and adolescents. European Journal of Endocrinology 2004151 127-133. (https://doi.org/10.1530/eje.0.1510127)

36 de Onis M, Onyango AW, Borghi E, Siyam A, Nishida C \& Siekmann J. Development of a WHO growth reference for school-aged children and adolescents. Bulletin of the World Health Organization 200785 660-667. (https://doi.org/10.2471/ blt.07.043497)

37 Matthews DR, Hosker JP, Rudenski AS, Naylor BA, Treacher DF $\&$ Turner RC. Homeostasis model assessment: insulin resistance and beta-cell function from fasting plasma glucose and insulin concentrations in man. Diabetologia 198528 412-419. (https://doi. org/10.1007/bf00280883)

38 Cornejo MP, Castrogiovanni D, Schioth HB, Reynaldo M, Marie J, Fehrentz JA \& Perello M. Growth hormone secretagogue receptor signalling affects high-fat intake independently of plasma levels of ghrelin and LEAP2, in a 4-day binge eating model. Journal of Neuroendocrinology 201931 e12785. (https://doi.org/10.1111/ jne.12785) 
39 Demsar J, Curk T, Erjavec A, Gorup C, Hocevar T, Milutinovic M, Mozina M, Polajnar M, Toplak M, Staric A et al. Orange: data mining toolbox in Python. Journal of Machine Learning Research 201314 2349-2353.

40 Daniels SR. Complications of obesity in children and adolescents. International Journal of Obesity 200933 S60-S65. (https://doi. org/10.1038/ijo.2009.20)

41 Marzullo P, Verti B, Savia G, Walker GE, Guzzaloni G, Tagliaferri M, Di Blasio A \& Liuzzi A. The relationship between active ghrelin levels and human obesity involves alterations in resting energy expenditure. Journal of Clinical Endocrinology and Metabolism 200489 936-939. (https://doi.org/10.1210/jc.2003-031328)

42 Tentolouris N, Kokkinos A, Tsigos C, Kyriaki D, Doupis J, Raptis SA \& Katsilambros N. Differential effects of high-fat and highcarbohydrate content isoenergetic meals on plasma active ghrelin concentrations in lean and obese women. Hormone and Metabolic Research 200436 559-563. (https://doi.org/10.1055/s-2004-825761)
43 Haqq AM, Farooqi IS, O'Rahilly S, Stadler DD, Rosenfeld RG, Pratt KL, LaFranchi SH \& Purnell JQ. Serum ghrelin levels are inversely correlated with body mass index, age, and insulin concentrations in normal children and are markedly increased in Prader-Willi syndrome. Journal of Clinical Endocrinology and Metabolism 200388 174-178. (https://doi.org/10.1210/jc.2002021052)

44 Wilasco MI, Goldani HA, Dornelles CT, Maurer RL, Kieling CO, Porowski M \& Silveira TR. Ghrelin, leptin and insulin in healthy children: relationship with anthropometry, gender, and age distribution. Regulatory Peptides 2012173 21-26. (https://doi. org/10.1016/j.regpep.2011.08.013)

45 Hassouna R, Zizzari P, Tomasetto C, Veldhuis JD, Fiquet O, Labarthe A, Cognet J, Steyn F, Chen C, Epelbaum J et al. An early reduction in $\mathrm{GH}$ peak amplitude in preproghrelin-deficient male mice has a minor impact on linear growth. Endocrinology 2014155 3561-3571. (https://doi.org/10.1210/en.2014-1126)

Received 25 August 2019

Revised version received 20 November 2019

Accepted 26 November 2019 